\title{
ARTÍCULO
}

\section{La prohibición de Ébano swing y Cachita en el primer franquismo (Circular 98): mucho más que la simple censura de dos temas musicales}

\section{The banning of Ébano swing and Cachita in the early years of the Franco regime (Circular 98): much more than the simple censoring of two musical numbers}

\author{
Fernando Centenera Sánchez-Seco \\ Área de Filosofía del Derecho \\ Facultad de Derecho \\ Universidad de Alcalá
}

Fecha de recepción 21/06/2019 | De aceptación: 01/12/2019 | De publicación: 27/12/2019

\section{RESUMEN.}

Este trabajo centra la atención en la Circular 98, que prohibió los temas musicales Ébano swing y Cachita durante el primer franquismo. El estudio analiza la medida desde la perspectiva del totalitarismo, considera las causas que suscitaron la fijación de la censura en los dos temas citados, y los motivos que pudieran explicar circunstancias tales como la no proliferación de prohibiciones en el mismo sentido. También se tratan numerosas deficiencias normativas, tanto de la Circular 98 como de otras regulaciones dedicadas a la censura musical, así como la eficacia de la prohibición. Finalmente se exponen varias conclusiones.

PALABRAS CLAVE.

Franquismo, totalitarismo, arbitrariedad, prohibición, inconsistencia, imprecisión, swing.

\section{ABSTRACT.}

This article focuses on the 98th Circular which banned the musical numbers Ébano swing and Cachita in the early years of the Franco regime. It analyses the measure from the perspective of totalitarianism and ponders what led the censor to prohibit both numbers and why such prohibitions did not proliferate. It also studies a number of regulatory shortcomings in the $98^{\text {th }}$ Circular itself and in other legislation concerning the censorship of music, as well as assessing the efficacy of prohibition. Some conclusions bring the article to an end.

\section{KEY WORDS.}

Francoism, totalitarianism, arbitrariness, prohibition, inconsistency, imprecision, swing. 
SUMARIO: 1. Introducción; 2. Una muestra de totalitarismo; 3. Una censura arbitraria; 4. Sobre la contextualización de la prohibición en el ámbito radiofónico y la escasez de prohibiciones en la misma línea; 5. Deficiencias normativas; 5.1. La Circular 98; 5.2. El análisis con respecto a otras normas; 6. La eficacia de la censura; 7. Conclusiones; 8. Fuentes; 8.1. Bibliografía; 8.2. Catálogos; 8.3. Documentos de archivo; 8.4. Hemeroteca; 8.5. Normas y otras disposiciones publicadas; 8.6. Recursos sonoros; 8.7. Recursos web no recogidos en las relaciones anteriores.

\section{Introducción ${ }^{1}$}

El tema del jazz durante el franquismo no ha reclamado especialmente la atención de los estudios hasta las décadas más recientes. Antes también encontramos alguna referencia interesante ${ }^{2}$, pero es en el periodo citado inicialmente cuando se aprecia un interés decidido por la cuestión. Muestra de ello ofrecen los trabajos de Pérez Zalduondo ${ }^{3}$, Pujol Baulenas ${ }^{4}$ e Iglesias $^{5}$, que se desarrollan principalmente en los planos histórico, musicológico y sociológico. Este trabajo se enmarca en la temática presentada, concretamente en el primer franquismo, con el fin de analizar una norma administrativa que hemos localizado en el Archivo General de la Administración (en adelante AGA). Nos referimos a la Circular 98 que, al menos hasta donde conocemos, se considera por primera vez en este estudio. En ella se prohíben dos temas enmarcados en la música swing ${ }^{6}$ : Ébano swing y Cachita. Se trata de una disposición más, procedente de un aparato de censura que se venía forjando desde los inicios de la guerra civil.

\footnotetext{
${ }^{1}$ Quisiera mostrar mi agradecimiento al profesorado que me ha transmitido sus apreciaciones y recomendaciones sobre la temática del trabajo, así como a quienes han realizado las evaluaciones.

${ }^{2}$ Probablemente una de las más representativas sea la siguiente: GARCÍA MARTÍNEZ, J. M.; Del fox-trot al jazz flamenco. El jazz en España: 1919-1996, Madrid, Alianza Editorial, 1996.

${ }^{3}$ Que cuenta con numerosos estudios sobre la música durante el franquismo, en los que se trata el jazz en ocasiones. Citamos a continuación su tesis doctoral: PÉREZ ZALDUONDO, G.; La música en España durante el franquismo a través de la legislación (19361951), [Tesis Doctoral], [Granada], Universidad de Granada, 2002 (CD).

${ }^{4}$ Autor del siguiente trabajo: PUJOL BAULENAS, J.; Jazz en Barcelona. 1920-1965, Barcelona, Almendra Music, 2005.

${ }^{5}$ Que cuenta con una producción que culmina con una excelente monografía sobre el jazz en el franquismo: IGLESIAS, I.; La modernidad elusiva. Jazz, baile y política en la Guerra Civil Española y el Franquismo (1936-1968), Madrid, Consejo Superior de Investigaciones Científicas, 2017.

${ }^{6}$ El swing podría enmarcarse en el jazz, aunque, como veremos, la censura del régimen lo consideró de forma particular.
} 
En 1936 Franco asumió la dirección del ejército sublevado y poco después creó una Junta Técnica de Estado, con el fin de establecer un sistema administrativo básico ${ }^{7}$, en el que la propaganda y la censura jugarían un papel muy relevante. El ámbito normativo daría cuenta de aquel planteamiento con numerosas disposiciones; entre ellas, un Decreto de 1937 en cuyo texto se manifestaba la importancia de reglamentar la propaganda, para acabar con las “doctrinas disolventes" de los años más recientes ${ }^{8}$. Con tal fin la norma creaba la Delegación del Estado para Prensa y Propaganda, dirigida por un delegado que tendría entre sus atribuciones las de coordinar las estaciones de radio, establecer normas de censura y dirigir la propaganda en diferentes ámbitos, entre ellos, el radiofónico ${ }^{9}$. Los cambios en el sistema serían frecuentes. A finales de 1938 los asuntos relativos a la prensa y la propaganda serían competencia de una Subsecretaría que comprendía los Servicios Nacionales relativos a dichos contextos, y que dependía del Ministerio de Gobernación (antes de Interior) ${ }^{10}$. Meses después, se crearía en el Servicio Nacional de Propaganda una Sección de Censura destinada a controlar numerosos ámbitos ${ }^{11}$. De este modo, el aparato represor se iba conformando al son de los intereses del poder, pero encontraría su impulso definitivo tiempo después, con la aparición del órgano que emitió la disposición en la que nos centramos.

La llegada de la dictadura marcaría la ruptura con los periodos constitucionales precedentes. Tal circunstancia da buena cuenta de las características del orden jurídico que se iba a imponer a partir de entonces, además del proceder del régimen en dicho ámbito. El rechazo al constitucionalismo liberal de 1869 y democrático de 1931 conllevaba varias consecuencias. De un lado, privaba a la sociedad de la evolución que la había venido conformando con aquellas experiencias ${ }^{12}$, y con ello de las libertades y la representación ${ }^{13}$. De otro lado, también supuso un ataque al Derecho internacional que, no obstante,

\footnotetext{
${ }^{7}$ NÚÑEZ DÍAZ-BALART, M.; “Las palabras como armas: la propaganda en la Guerra Civil”, en Timoteo Álvarez, J. (ed.), Historia de los medios de comunicación en España. Periodismo, imagen y publicidad (1900-1990), Barcelona, Editorial Ariel, 1989, p. 179.

8 “Decreto número 180”, Boletín Oficial del Estado, 89, 17 de enero de 1937, p. 134.

${ }^{9}$ Ibídem. Sobre el breve desarrollo que presentamos en el texto, y las personas que asumieron cargos en las diversas formulaciones del sistema, puede consultarse PIZARROSO QUINTERO, A.; "Política informativa: información y propaganda (1939-1966)", en Timoteo Álvarez, J. (ed.), Historia de los medios de comunicación en España. Periodismo, imagen y publicidad (1900-1990), Barcelona, Editorial Ariel, 1989, pp. 235, 236.

10 “Ley de 29 de diciembre de 1938”, Boletín Oficial del Estado, 183, 31 de diciembre de 1938, p. 3216.

11 "Orden de 15 de julio de 1939 creando una Sección de Censura dependiente de la Jefatura del Servicio Nacional de Propaganda y afecta a la Secretaría General”, Boletín Oficial del Estado, 211, 30 de julio de 1939, p. 4120.

${ }^{12}$ CLAVERO, B.; Evolución histórica del constitucionalismo español, Madrid, Tecnos, 1985, pp. 146, 147.

${ }^{13}$ CLAVERO, B.; Manual de historia constitucional de España, Madrid, Alianza Universidad Textos, 1989, p. 234.
} 
ya había tenido lugar durante la guerra con los bombardeos a la población civil en los que participaron Alemania e Italia. Con ello se vulneraba el derecho de la Sociedad de Naciones reconocido en la Constitución de 1931 y que también formaba parte del derecho positivo ${ }^{14}$. Estas circunstancias marcarían las líneas secundadas por el sistema jurídico posterior, pero también anuncian las deudas pendientes con el Eje, que en lo sucesivo dejarían su impronta en diversos ámbitos, entre ellos, el cultural, como veremos en este estudio.

La prohibición en la que nos centramos procede de la Vicesecretaría de Educación Popular; un órgano de la Falange que había sido creado con una ley de $1941^{15}$, del cual dependían una Delegación Nacional de Prensa y una Delegación Nacional de Propaganda. Esta última, a su vez, contaba con diferentes secciones, entre ellas, la de radiodifusión, que es el ámbito en el cual se enmarca la prohibición que presentamos, al menos en su formulación inicial. Aunque en este estudio no tenemos espacio suficiente para plantear con detalle el organigrama establecido para la censura, con vistas a contextualizar los contenidos posteriores debemos referirnos, siquiera brevemente, a las Delegaciones Provinciales ${ }^{16}$, desde donde se llevaba a cabo la censura de manera más directa en diferentes ámbitos. A todas ellas se remitió la prohibición que nos va a ocupar, con el fin de que se transmitiera a las emisoras y se hiciera efectiva.

Entendemos que el hecho de centrar la atención en la norma que venimos presentando, de por sí aporta interés, por cuanto hasta el momento no se ha dado a conocer. No obstante, este trabajo pretende ir más allá de la mera exposición descriptiva de aquella, para ofrecer diversos planteamientos en torno a la

\footnotetext{
${ }^{14}$ CLAVERO, B.; "Derecho bajo asedio, 1936-1939: República Española y Sociedad de Naciones en el escenario europeo entre constitucionalismo y dictadura", Quaderni Fiorentini per la storia del pensiero giuridico moderno, 47, 2018, pp. 262, 279, 291, http://www.centropgm.unifi.it/cache/quaderni/47/0263.pdf. En esta fuente se constata que la República presentó pruebas ante la Sociedad de Naciones considerando la participación militar de Italia, pues Alemania había dejado para entonces aquella organización (p. 284). En este último contexto, a finales de la década de los treinta se presentaría desde el plano doctrinal un "nuevo Derecho internacional" ordenado en torno al Reich; palabra que sustituiría a la de Estado, entre otras cosas, a causa de las políticas expansionistas del nazismo. Sobre estas cuestiones STOLLEIS, M.; La textura histórica de las formas políticas, Gutiérrez Gutiérrez, I. (trad.), Madrid, Marcial Pons, 2011, p. 91.

15 "Ley de 20 de mayo de 1941 por la que se transfieren los Servicios de Prensa y Propaganda a la Vicesecretaría de Educación de F.E.T. y de las J.O.N.S., que se crea por la presente ley”, Boletín Oficial del Estado, 142, 22 de mayo de 1941.

${ }^{16}$ BERMEJO SÁNCHEZ, B.; "La Vicesecretaría de Educación Popular (1941-1945): un «ministerio» de la propaganda en manos de Falange", Espacio, Tiempo y Forma, Serie $V$ Historia Contemporánea, IV, 1991, pp. 74 y ss., http://espacio.uned.es/fez/eserv.php?pid=bibliuned:ETFSerie5-16946BB6-A601-59A9-CD02-AB4BD2DA2738\&dsID=Documento.pdf; MONTORO FRAGUAS, A.; "La Circular 95/42. Un documento singular en la censura de la radio española", Revista General de Información y Documentación, 6/1, 1996, p. 272.
} 
misma $^{17}$. En primer lugar, presentamos un análisis desde la perspectiva del totalitarismo, seguido de un espacio dedicado a los motivos que pudieran haber suscitado la fijación de la censura en los dos temas citados. A continuación, tratamos de encontrar las razones de circunstancias tales como que la norma fuera únicamente referida al ámbito radiofónico, o que no proliferaran otras en la misma línea. También ofrecemos varios análisis que ponen de manifiesto importantes deficiencias desde el punto de vista normativo, tanto en lo que respecta a la Circular 98, como a propósito de otras regulaciones coetáneas; y finalmente nos detenemos en la eficacia de la medida. Los contenidos desarrollados en estos espacios se enmarcan principalmente en el ámbito de la filosofía política y jurídica ${ }^{18}$.

\section{Una muestra de totalitarismo}

La palabra 'totalitarismo' no tiene un significado unívoco. En principio, podemos partir de lo que establecía la propaganda del régimen, donde a propósito de la exposición del Estado totalitario se alude a la patria como "unidad total", representada por el yugo superpuesto a las flechas, que a su vez simbolizan la guerra contra lo enemigo ${ }^{19}$. Considerado desde la perspectiva musical, tal planteamiento se traduce en la exclusividad de un tipo o tipos de música que haría suyos el régimen, y la exclusión de los considerados enemigos. Desde este punto de vista, la prohibición que nos interesa se presenta como una manifestación de totalitarismo, consistente en desechar la música swing, identificada con Estados Unidos. A propósito de ello, conviene recordar que meses antes de que apareciera la norma, Alemania había declarado la guerra a aquel país ${ }^{20}$, y que en España, como veremos más adelante, también en sintonía con el conflicto bélico, se dejó sentir la influencia nazi en el tema que nos ocupa.

\footnotetext{
${ }^{17}$ Consideramos también otros documentos de diferente tipo relacionados con la norma en cuestión. A la hora de tratar la documentación hemos seguido las siguientes pautas. En las transcripciones literales seguimos la grafía original. Utilizamos la misma rutina en la cita de documentos, si bien en este caso el formato de las fechas aparece unificado. Por otra parte, cuando la referencia no tiene título proponemos uno entre corchetes, escribimos mayúsculas iniciales cuando el texto se dispone totalmente en mayúsculas, y utilizamos comillas angulares cuando el signo tipográfico aparece dentro de entrecomillado.

${ }^{18}$ En trabajos anteriores hemos abordado el tema del jazz en el III Reich, siguiendo un planteamiento metodológico que tiene puntos en común con el utilizado en el trabajo que aquí se presenta. Principalmente, en lo que respecta a la siguiente referencia: CENTENERA SÁNCHEZ-SECO, F.; "El jazz en el III Reich: un análisis sobre los fracasos en la legalidad y la justicia”, Derechos y Libertades, 36, 2017, pp. 249-279, https://e-archivo.uc3m.es/bitstream/handle/10016/26252/DyL-2017-36-centenera.pdf?sequence=1.

${ }^{19}$ Informe del Cursillo para Capacitacion de Propagandistas Organizado por esta Delegacion Provincial [de Albacete] y Celebrado en los Dias 9 al 15 de Noviembre de 1942. Día 11 (3ª sesión de trabajo). AGA (03)49.01 21/01531.

${ }^{20}$ KERSHAW, I.; Decisiones trascendentales. De Dunquerque a Pearl Harbour (1940-1941). El año que cambió la historia, Escartín, A. (trad.), Barcelona, Ediciones Península, 2008, pp. 542 y ss.
} 
Desde el punto de vista de las aportaciones doctrinales contemporáneas el totalitarismo se presenta del siguiente modo. De un lado, se entiende que se opone al Estado de Derecho, y que por ello vulnera el imperio de la ley y los derechos fundamentales ${ }^{21}$. Curiosamente, tiempo antes de que apareciera la norma que nos interesa se había manifestado la intención crear un Estado totalitario, una vez fusionada la Falange con el tradicionalismo. Quizá lo más paradójico de todo ello es que con vistas a tal fin, uno de los objetivos sería el de establecer un régimen jurídico considerado como "estado de derecho" 22 . Evidentemente, esta expresión debe entenderse como Estado con Derecho, y no como Estado de Derecho, conformado por las características citadas recientemente.

Si partimos de la característica expuesta, de nuevo en esta ocasión llegamos a la conclusión de que la prohibición que nos ocupa se enmarca en el totalitarismo, puesto que supone la vulneración de derechos (quizá uno de los más evidentes sea el de libertad de expresión en diferentes ámbitos), y también afectaciones al imperio de la ley. A estas últimas nos referiremos más adelante, en los espacios que reservamos para el análisis normativo.

Desde la misma parcela de análisis el totalitarismo se presenta también como un régimen en el que existe un partido único con una ideología considerada "verdad oficial", que se difunde con la fuerza y la persuasión en los medios de comunicación ${ }^{23}$. Se trata del "ojo omnisciente" del partido único que pretende conocer lo divino y la historia ${ }^{24}$; del fascismo que ataca al individualismo y abstencionismo liberales, sustituyéndolos por el organicismo y la intromisión totalitaria ${ }^{25}$. En tal planteamiento buena parte de las actividades económicas y profesionales se encuentran sometidas al Estado, cualquier falta se politiza y sobreviene el terror ${ }^{26}$. En relación a esto último cabría constatar que Arendt se refiere al

\footnotetext{
${ }^{21}$ DÍAZ, E.; Estado de derecho y sociedad democrática, Madrid, Cuadernos para el Diálogo, 1966, pp. 31 y 32 . Sobre el concepto de Estado de Derecho también STOLLEIS, M.; "La idea de Estado de Derecho", en Presno Linera, M. Á. (coord.), La metamorfosis del Estado y del Derecho, Oviedo, Junta General del Principado de Asturias, 2014, p. 42, https://www.unioviedo.es/constitucional/fundamentos/octavo/pdfs/Stolleis-EstadodeDerecho.pdf . Este trabajo da cuenta además de la ruptura con el Estado de Derecho que venía forjándose desde los años anteriores en Europa, y de su reconstrucción a partir de 1945; proceso este último en el cual, evidentemente, no participaría la dictadura franquista (pp. 43 y ss.).

22 PÉREZ ZALDUONDO, G.; op. cit., sin paginar.

${ }^{23}$ ARON, R.; Democracia y totalitarismo, González Castro, L. (trad.), Barcelona, Página Indómita, 2017, p. 291.

${ }^{24}$ STOLLEIS, M.; El ojo de la ley. Historia de una metáfora, Fernández-Crehuet, F. (trad.), Madrid, Marcial Pons, 2010, p. 76.

${ }^{25}$ DÍAZ, E.; op. cit., p. 29.

${ }^{26}$ ARON, R.; op. cit., pp. 291, 292. Sobre aspectos como los intereses económicos o el terror puede consultarse también DÍAZ, E.; op. cit., pp. 31, 32 .
} 
"terror total" 27 , y que en torno a ello se ha debatido acerca de si es posible advertir en el franquismo un control absoluto $^{28}$. A nuestro modo de ver, el régimen del que procedía la disposición que nos ocupa se adecúa a la estructura expuesta, si bien en relación al tema del control total cabría considerar lo siguiente. El mero hecho de entrar a regular la cuestión musical es, al menos, una prueba que evidencia las intenciones del régimen de llegar a todos los rincones con pretensiones de control. Tal planteamiento cobra especial relevancia, si tenemos en cuenta la escalada que estaba experimentando la censura en el periodo que contextualizó la prohibición que nos ocupa.

Una vez terminada la Guerra Civil, desde determinados ámbitos del régimen comenzaron a aparecer manifestaciones que mostraban una aversión creciente y cada vez más contundente con respecto al jazz. De nuevo, en esta ocasión, la mirada al exterior resulta sugerente. A mediados de 1940 el nazismo había logrado numerosas victorias en el conflicto bélico, que estaban alentando los planes de Japón para expandirse hacia el sur; país que, a su vez, pretendía reforzar la solidaridad con Alemania e Italia, y cuyo ejército contemplaba la posibilidad de entrar en guerra contra Estados Unidos ${ }^{29}$. Resulta interesante constatar que, precisamente en este momento, la prensa falangista informaba de la prohibición del jazz en Japón. Junto a ello, no se perdía la oportunidad de alentar medidas en el mismo sentido en ámbitos tales como las emisoras de radio ${ }^{30}$. Poco tiempo después, un Proyecto de Reorganización del Servicio de Propaganda de F.E.T. y de las J.O.N.S., lamentaba que la Falange no hubiera podido acabar con "ese mundo contrahecho y estéril de las novelas rosas, de los tangos, de las algaradas callejeras, del ritmo negro de los «dantzigs»"31. Más adelante, casi finalizado el documento,

\footnotetext{
${ }^{27}$ ARENDT, H.; Los orígenes del totalitarismo, Solana, G. (trad.), Madrid, Taurus Ediciones, 1974, p. 564. En la misma obra la autora no califica a la dictadura franquista de totalitaria (p. 389).

28 Pueden verse las líneas del debate en IGLESIAS, I.; "Performing the 'anti-spanish' body", en Johnson, B. (ed.), Jazz and Totalitarianism, New York and London, Routledge, 2017, pp. 159, 160; IGLESIAS, I.; La modernidad elusiva ..., pp. 15-16; PEDRO, J.; “"The purest essence of jazz' The Appropiation of Blues in Spain during Franco's Dictatorship”, en Johnson, B. (ed.), Jazz and Totalitarianism, New York and London, Routledge, 2017, pp. 174-176; y JOHNSON, B.; "Introduction”, en Johnson, B. (ed.), Jazz and Totalitarianism, New York and London, Routledge, 2017, pp. 3-5.

${ }^{29}$ KERSHAW, I.; op. cit., pp. 162-166.

30 “Notas. Declaración de Guerra". Falange, 8 de agosto de 1940, p. 1. Al parecer, las medidas todavía estaban presentes en 1943 , momento en el cual se publicó una lista de discos prohibidos, que no podrían venderse, y que tendrían que destruirse por parte de quienes los tuvieran. Sobre ello EFE; "En el Japón se prohibe la música anglosajona, especialmente de «jazz»”, La Nueva España, 15 de enero de 1943 , p. 5.

${ }^{31}$ DE URRUTIA, F.; Proyecto de Reorganización del Servicio de Propaganda de F.E.T. y de las J.O.N.S., sin fecha [probablemente de octubre de 1941, teniendo en cuenta la documentación adjunta]. AGA (03)48 21/00127.
} 
podemos leer lo que, a nuestro modo de ver, es una clara referencia al jazz, en conexión con los pretendidos objetivos anteriores ${ }^{32}$ :

"Completando esta actuación parece necesario recabar de todas las autoridades competentes la anulación implacable y según nuestras indicaciones de lo que aún queda, de lo que hemos dado en llamar «la poesía que destruye», como músicas sensibleras o de sensiblería angloizante".

Las prohibiciones no tardaron en llegar, aparecieron a mediados de 1942. Probablemente las más representativas sean la orden que vetaba interpretaciones de temas de música clásica con jazz ${ }^{33}$, y la Circular 95, que prohibió en la radio la música negra, el swing y los temas en idioma extranjero o que "puedan rozar la moral pública o el más elemental buen gusto" ${ }^{34}$. Sin embargo, la escalada de la censura fue más allá.

Coetáneamente aparecieron otras prohibiciones que centraban la atención en temas musicales concretos, buena parte de ellas en circulares, inmediatamente antes o después de la Circular 95 citada anteriormente. Así, la Circular 9435, que prohibía la emisión del tema Arroz con leche del Trío argentino Irustare. No se trata de una composición de jazz, de hecho, en la proscripción se cataloga musicalmente como ranchera, pero la norma resulta interesante, pues anuncia un modelo de prohibición que se secundaría en casos posteriores. Con el mismo formato también se prohibió la emisión, ejecución y difusión publicitaria de las Coplas del Espartero y las Sevillanas del Espartero ${ }^{36}$. Al año siguiente, con una fórmula parecida se ordenó no citar a Los Bocheros en sus interpretaciones musicales o anuncios de aquellas, y en todo concerniente a la propaganda ${ }^{37}$. Un mes y medio antes, aunque en esta ocasión simplemente recurriendo a una nota, se prohibía la emisión del tema Bésame mucho ${ }^{38}$.

\footnotetext{
32 Ibídem.

33 “Grupo de Música. Orden”, Boletín del Sindicato Nacional del Espectáculo, 5, agosto de 1942, p. 17.

${ }^{34}$ Circular 95. Normas sobre Censura Radiofonica, 17 de septiembre de 1942. AGA (03)49.01 21/00701.

${ }^{35}$ Circular 94. [Prohibición de Arroz con leche del Trío argentino Irustare], 16 de septiembre de 1942. AGA (03)49.01 21/00806.

${ }^{36}$ Circular 106. [Prohibición de las Coplas del Espartero y Sevillanas del Espartero], 21 de octubre de 1942. AGA (03)49.01 21/00806.

${ }^{37}$ Circular 156. [Prohibición de toda nominación a Los Bocheros], 5 de noviembre de 1943. AGA (03)49.01 21/00807.

38 [Nota con la prohibición de Bésame mucho], 21 de septiembre de 1943. AGA (3)60 21/00805.
} 
La Circular 98 apareció en el contexto normativo recientemente expuesto; concretamente, días después de la referencia citada en primer lugar. Como ya señalamos, procede de la Delegación Nacional de Propaganda y se dirige a las Delegaciones Provinciales de Educación Popular. En su texto podemos leer lo siguiente 39 :

"Esta Delegación Nacional ha dispuesto que, a partir de la recepción de la presente circular, todas las Emisoras Nacionales se abstengan de incluir en sus programas, tanto de música directa como registrada, los bailables titulados «Ebano Swing», fox-trot de S. Crespo y «Cachita» swing de R. Hernández.

Lo que deberás trasladar a las emisoras de tu jurisdicción, a los efectos consiguientes.”

Como decimos, esta intención de avanzar en la censura, alcanzando al ámbito musical y proscribiendo, ya no únicamente tipos de música, sino temas concretos de forma explícita, supone una manifestación de un régimen que, al menos como aspiración, pretendía ser totalitario en lo que respecta al control. Es cierto, no obstante, que una cosa es la intención y otra lo que realmente aconteció. En tal circunstancia están reparando estudios de los años más recientes, donde el análisis en torno al totalitarismo no atiende ya a los ideales de inicio, sino a la tensión entre aquellos y determinados aspectos de la vida cotidiana. Se trata, por tanto, de diagnosticar la dinámica totalitaria en ámbitos concretos de la realidad $^{40}$. Más adelante plantearemos varios desarrollos que ponen de manifiesto tensiones en el sentido apuntado, y que también darán cuenta de la eficacia de la medida.

\section{Una censura arbitraria}

Como sabemos, la Circular 98 prohibió en el ámbito radiofónico los temas Ébano swing y Cachita. Tal circunstancia suscita una pregunta ineludible: ¿cuáles fueron las razones que llevaron a centrar la atención en las composiciones citadas $?^{41}$ La reflexión sobre esta cuestión resulta interesante por diferentes motivos. En un primer momento, podría pensarse que fue la palabra 'swing', que aparece al final del título del primer tema, la que levantó las alarmas. Sin embargo, una revisión de referencias

\footnotetext{
${ }^{39}$ Circular 98. [Prohibición de Ébano swing y Cachita], 22 de septiembre de 1942. AGA (3)49.01 21/00806.

${ }^{40}$ Sobre estas cuestiones JOHNSON, B.; op. cit., pp. 3-6.

${ }^{41}$ No nos referimos aquí a los fundamentos que podrían considerarse en términos generales en relación a la prohibición del swing, cuestión que podría abordarse en base a un análisis de los caracteres del fascismo que se consideran en DÍAZ, E.; op. cit, pp. 31 y ss.
} 
musicales del momento demuestra que tal característica se aprecia también en numerosos títulos. Sin intención alguna de exhaustividad, podríamos citar los siguientes: Tiempo y swing ${ }^{42}$, Harlem swing ${ }^{43}$, Yodel en swing ${ }^{44}$ o Swing $39^{45}$. Es cierto que el régimen identificó el swing con Estados Unidos, y en este sentido podría decirse que el último de los temas habría pasado la censura sin problemas, dado que se enmarca en el jazz manouche genuino de Francia. Sin embargo, los temas segundo y tercero se interpretan por formaciones españolas, del mismo modo que Ébano swing, y se pueden agrupar bajo la misma tipología musical. Por lo demás, con mayor razón podría pensarse en la censura del citado en primer lugar, que además de descubrir en su título la música en la que se enmarca, se interpreta por la Orquesta de Lionel Hampton, un paradigma del jazz norteamericano. Lo mismo podría decirse del segundo tema, cuyo título, además de hacer referencia al swing, cita también al barrio por antonomasia del jazz en Nueva York: Harlem.

Por otra parte, en la búsqueda de posibles razones de la censura cabría considerar también que, quizá, aquella podría haber traído causa de los solos instrumentales del tema Ébano swing (según nuestra interpretación, de trompeta y saxo principalmente). En la prohibición de la música que nos ocupa es más que probable la influencia nazi ${ }^{46}$, y en este contexto se tuvo en cuenta la improvisación a la hora de proscribir el jazz ${ }^{47}$. Sin embargo, de nuevo este planteamiento debería ponerse en cuestión por varias razones. Por una parte, aun cuando en el tema pueden apreciarse las características citadas, su tipología musical encaja más bien en el straight que en el hot; siendo especialmente relevante la improvisación en este último tipo de jazz. Además, en lo que respecta al tema Cachita, también prohibido, debemos decir que no se caracteriza precisamente por la improvisación. Por otra parte, temas como los que

\footnotetext{
${ }^{42}$ Orquesta Lionel Hampton, "My muchachito (my buddy)/Tiempo y swing”, Barcelona, Compañía del Gramófono Odeón, 1941.78 rpm. Biblioteca Nacional de España (en adelante BNE)/Ds/73/11.

${ }^{43}$ Orquesta Andrés Moltó, "Harlem swing/Engaños”, Barcelona, Compañía del Gramófono Odeón, 1942. 78 rpm. BNE/Ds/56/14.

${ }^{44}$ Luis Rovira y su Orquesta, Emil, vocalista, "Yodel en swing/Bailando en la azucarera (Swingin' at the sugar bowl)", Barcelona, Compañía del Gramófono Odeón, 1942. 78 rpm. BNE/ Ds/56/8.

45 Quinteto del Hot Club de Francia, “Jeepers creepers/Swing 39”, San Sebastián, Fábrica de Discos Columbia, 1943.78 rpm. $\mathrm{BNE} / \mathrm{Ds} / 131 / 15$.

${ }^{46}$ La cuestión probablemente daría para otro estudio, pero aquí únicamente podemos citar algunas de las manifestaciones más relevantes. Quizá resulte significativo constatar que en 1935 el jazz se prohibió en la radio alemana y que tiempo después se proscribieron temas concretos en relaciones conjuntas. La primera medida puede verse en HADAMOVSKY, E.; "Die Rede auf der Intendantentagung", https://grammophon-platten.de/page.php?281.1; y la segunda en "Erste Liste unerwünschter musikalischer Werke", German Propaganda Archive, https://research.calvin.edu/german-propaganda-archive/banned.htm.

${ }^{47}$ Consideramos la cuestión en CENTENERA SÁNCHEZ-SECO, F.; "El jazz en el III Reich...”, p. 255; CENTENERA SÁNCHEZSECO, F.; "The Frankfurt Hot Club jazz band under the Nazis: much more than music", Law and Humanities, 12/2, 2018, pp. 192, 194, 195, https://www.tandfonline.com/doi/abs/10.1080/17521483.2018.1514948.
} 
citamos anteriormente tienen un nivel de improvisación parecido (Yodel en swing), superior (Harlem swing) o muy superior (Tiempo y swing). Sin embargo, no fueron proscritos.

Desde el punto de vista procedimental, criterios como los recientemente expuestos no habrían logrado una censura uniforme, pues hay más temas de swing que aquellos que mencionan dicha palabra en su título $\mathrm{y}$, por otra parte, existían temas de swing sin apenas improvisación. Sin embargo, tal planteamiento probablemente habría supuesto una contribución para una censura pautada en cierto sentido. No obstante, no aconteció de tal modo, y la pregunta que planteamos al comienzo de este espacio sigue sin estar respondida.

Tras analizar diferente documentación, a nuestro modo de ver la prohibición que nos ocupa se gestó teniendo en cuenta los siguientes aspectos. Por una parte, nos encontramos con que el tema Ébano swing se debió editar entre junio y comienzos de septiembre de $1942^{48}$; es decir, justo en el periodo en el que se estaba orquestando la censura contra el jazz. Por otra parte, el tema en cuestión había ocupado numerosos espacios radiofónicos. Un análisis de varios cuadernos de emisiones descubre su presencia en programas radiados los días anteriores a la aparición de la prohibición. En este sentido, podemos, por ejemplo, referirnos a un evento retransmitido por Radio Madrid desde el Parque Barceló, el día 5 de septiembre de 1942. En él la Orquesta California interpretaría un repertorio con varias referencias, entre ellas, una que aparece citada como sigue: "«Ebano», fox de Crespo"49. La entrada, que sin duda alude al tema que estamos considerando, aparece también en otro programa de Radio España pocos días después, el 12 de septiembre de 1942; en esta ocasión a cargo de la Orquesta Filmófono ${ }^{50}$.

Como habrá podido observarse, en el párrafo anterior hemos reproducido literalmente la entrada localizada en los cuadernos de emisiones. Esta disposición es totalmente intencionada. Resulta muy curioso que en ambos casos se omitiera la palabra 'Swing' del título que, como hemos visto, se enuncia simplemente como 'Ebano'. Consideramos que muy probablemente, ello se deba al conocimiento que

\footnotetext{
${ }^{48} \mathrm{Al}$ menos la interpretación de Tejada y su Gran Orquesta que, como después veremos, resulta determinante para entender cómo se hizo la censura, no aparece en el Catálogo general de discos Columbia publicados hasta mayo de 1942, San Sebastián, Fábrica de Discos Columbia, [1942], http://www.eresbil.com/web/uploads/archivosGeneradorWeb/Catalogos/erelib_NL0214COL_01 v.pdf. Sin embargo, sí que encontramos catalogado el disco en Recopilación de los discos "Columbia" publicados des̄e $1^{\circ}$ de junio de 1942 hasta 30 de abril de 1944, San Sebastián, Fábrica de Discos Columbia, http://www.eresbil.com/web/uploads/archivosGeneradorWeb/Catalogos/erelib NL0214COL_02 v.pdf.

49 [Cuaderno de emisiones de] Radio Madrid, 5 de septiembre de 1942. AGA (03)48 21/00012.

50 [Cuaderno de emisiones de] Radio España, 12 de septiembre de 1942. AGA (03)48 21/00007.
} 
se tenía de la creciente aversión del régimen frente al jazz. La omisión citada que, como señalaremos más adelante, no es exclusiva de este caso, pudo haber sido un recurso para evitar posibles censuras. De ser acertado tal planteamiento, su consideración desde el plano normativo resulta muy interesante, pues nos encontramos con la intención de tratar de salvar la censura, aun a pesar de que entonces no había aparecido regulación alguna al respecto. En ello, probablemente deba verse una muestra de la forma de proceder del régimen en el momento, en un contexto donde no se tenían precisamente en cuenta normas, porque no existían (recordemos que las consideradas en este trabajo son posteriores a las fechas en las que se emitieron los programas radiofónicos citados), sino las manifestaciones que el régimen iba dejando en su propaganda. Consideramos que tal circunstancia ilustra el planteamiento que advierte en los sistemas de control no únicamente represión, sino también medidas en el ámbito de la comunicación que surten efectos en la producción del discurso, y cuyo resultado es la autocensura ${ }^{51}$.

No obstante, debemos apuntar que la omisión que venimos considerando no se observa en todo caso. Así acontece con la presentación que se hizo del tema Ébano swing, interpretado en esta ocasión por la Orquesta Gil Serrano, en un espacio de Radio Madrid dedicado a la música moderna y titulado "Musica y Orquestas de Hoy". En esta ocasión se trata de edulcorar la composición, sin duda -entendemosatendiendo al rechazo que estaba mostrando el régimen. No obstante, probablemente a consecuencia de ello, su presentación aparece provista de desafortunados comentarios racistas. Debemos señalar además que el documento consultado aporta una información muy interesante para responder a los interrogantes que nos vienen ocupando, si bien aquella también se confirma con el desarrollo recientemente expuesto. Según el guion de dicho espacio, Ébano swing había alcanzado popularidad. Merece la pena la transcripción literal del siguiente extracto, tomado del programa radiofónico que incluía el tema ${ }^{52}$ :

"Otro nuevo aspecto de la música negra, puesta de acuerdo con los gustos más exigentes, es el fox «Ébano Swing». La música negra no es ya dislocada ni absurda. En vez de extraviarse en saltos se desata en una suave cadencia que invita a bailar, a bailar como los negros de hoy, ya trasplantados y arraigados en la civilización blanca. «Ébano Swing» es un fox medio tiempo,

\footnotetext{
${ }^{51}$ Sobre la cuestión puede verse BUNN, M.; "Reimagining Repression: New Censorship Theory and After", History and Theory, 54, 2015, pp. 37, 38.

52 [Cuaderno de emisiones de] Radio Madrid, 10 de septiembre de 1942. AGA (03)48 21/00012.
} 
del que hace una creación la orquesta «Gil Serrano». Oigámosla en su interpretación de «Ébano Swing»...."

La lectura detenida del texto, teniendo en mente la prohibición inminentemente posterior, invita a pensar que sus connotaciones racistas no jugaron el papel disuasorio, probablemente pretendido para sortear la censura. Es más, el anuncio del tema como el resultado de la presencia de la cultura negra en la blanca, podría haber sido un aliciente más para plantear la prohibición.

En base a todo lo dicho, cabría concluir que, probablemente, la Delegación Nacional de Propaganda centró la atención en Ébano swing por la popularidad que estaba teniendo. Con ello se evidencia la arbitrariedad con la que se estaba llevando a cabo la censura, pero eso no es todo. Dicha forma de proceder se confirma si reparamos en la cuestión de por qué se prohibió también el tema Cachita.

El texto de la Circular 98 no ofrece información alguna para poder encauzar una posible respuesta a la cuestión planteada. Por otra parte, en nuestra investigación no hemos localizado documentación que pruebe en esta ocasión un desarrollo como el recientemente expuesto a propósito de Ébano swing. No obstante, pensamos que, prácticamente con total seguridad, la razón de que la norma también incluyera el tema Cachita fue la que planteamos a continuación. Es bastante probable que quienes realizaron la censura hubieran tenido en sus manos el 78 revoluciones por minuto (en adelante rpm) ${ }^{53}$ de Tejada y su Gran Orquesta, que incluye los dos temas $\operatorname{citados}^{54}$; de otro modo, difícilmente puede explicarse que el veto hubiera incidido precisamente en aquellos. Muy probablemente, con el objetivo de redactar la prohibición del afamado Ébano swing se buscó un registro discográfico que lo recogiera. Al menos hasta donde llegamos a conocer, existían dos grabaciones; por una parte, la de Tejada y su Gran Orquesta $^{55}$ recientemente citada, y por otra parte, la de Raúl Abril con la Orquesta Martín de la Rosa ${ }^{56}$. Aleatoriamente, se escogió la primera, recogida en un $78 \mathrm{rpm}$ que incluía en su otra cara el tema Cachita. Una vez examinado, se debió determinar no únicamente la prohibición del tema que estaba consiguiendo fama en espectáculos y emisoras, sino también la del que aparecía en la otra cara del

\footnotetext{
${ }^{53}$ Se trata del formato habitual en el que se editaban los discos en el momento cronológico que consideramos.

54 Tejada y su Gran Orquesta del Pasapoga de Madrid, "Ebano Swing/Cachita”, San Sebastián, Columbia, sin fecha. 78 rpm. Colección privada.

${ }^{55}$ Ibídem.

${ }^{56}$ Raúl Abril, con la Orquesta Martín de la Rosa, "Madrugada: fox lento de la película, Ritmo en las ondas/Ébano swing”, Barcelona, Compañía del Gramófono Odeón, 1942.78 rpm. BNE/Ds/80/8.
} 
disco; simplemente, porque tenía la calificación de swing. A continuación del título Cachita el $78 \mathrm{rpm}$ informa del compositor y de la tipología musical del tema; concretamente, como sigue: "(R. Hernández) «Swing»”. Consideramos, por tanto, que en este segundo caso la prohibición se debió a que el tema en cuestión estaba en un $78 \mathrm{rpm}$ que recogía otro que pretendía prohibirse (Ébano swing), y a que aquel tenía la calificación de swing en el registro citado.

\section{Sobre la contextualización de la prohibición en el ámbito radiofónico y la escasez de} prohibiciones en la misma línea

Como señalamos anteriormente, la prohibición que venimos analizando podría considerarse una muestra de las pretensiones totalitarias del régimen. Sin embargo, aquellas, entendidas en el último sentido presentado, entran en tensión con circunstancias tales como que la prohibición se planteara en el ámbito radiofónico, o la escasez de prohibiciones dispuestas en el mismo formato. En este apartado presentamos algunos planteamientos que podrían servir para explicar las circunstancias citadas.

Como sabemos, el veto de la Circular 98 únicamente alcanza a las emisoras de radio. En base a ello, cabría, por ejemplo, preguntarse por qué la Delegación Nacional de Propaganda no extendió la prohibición también al contexto discográfico que, por cierto, en todo momento estuvo bajo el control de la censura ${ }^{57}$. El análisis centrado en la discográfica Columbia, que editó los temas que nos interesan, puede resultar especialmente interesante. En principio, conviene señalar que desde 1936, San Sebastián, donde se ubicaba Columbia, había sido el centro neurálgico de la propaganda del bando sublevado, que utilizó a la discográfica para tal cometido. Allí se editó en disco el himno de la Falange, el Cara al $\mathrm{Sol}^{58}$, que sería radiado hasta la saciedad en los años siguientes. Tiempo después, el régimen seguiría llevando a cabo numerosas transacciones comerciales en las que, por ejemplo, solicitaría a Columbia registros del Himno Nacional, la Cabalgata militar ${ }^{59}$, la Canción de Trilla, los Canteros de Covadonga o Segadores ${ }^{60}$. Quizá todo ello podría haber propiciado cierta connivencia a la hora de abordar la censura en el ámbito que ahora centra nuestra atención, aunque también es cierto que años

\footnotetext{
${ }^{57}$ Oficio de la Delegación Nacional de Propaganda. P. Oral E. Musical, 22 de mayo de 1942. AGA (03)49.01 21/00102.

58 "Los comienzos de la industria discográfica en Euskal Herria", ERESBIL. Archivo vasco de la música, http://www.eresbil.com/web/tema-inddiseh/Pagina.aspx?moduleID=2419\&lang=es.

59 [Solicitud de envío urgente de discos a la Fábrica de Discos Columbia], 28 de julio de 1943. AGA (03)49.01 21/01836.

${ }^{60}$ [Solicitud de envío urgente de discos a la Fábrica de Discos Columbia], 28 de abril de 1943. AGA (03)49.01 21/01836.
} 
antes, el régimen había demostrado que todo lo anterior no habría obstado para prohibir a la discográfica propuestas que fueran contrarias a sus intereses ${ }^{61}$.

En todo caso, y aun cuando lo dicho pudiera servir para conformar en parte la respuesta que buscamos, deben considerarse otras posibles causas que contribuyan a seguir explicando las cuestiones que nos ocupan en este espacio. No obstante, antes de continuar no podemos dejar de significar la paradoja que supone considerar al swing una "mixtificación comercial" de Estados Unidos ${ }^{62}$; y al tiempo participar en el mercado discográfico, como así lo estaba haciendo inevitablemente el régimen, a consecuencia del desarrollo de su sistema de propaganda. En este punto, resulta casi ineludible recordar que el fascismo supone una manifestación del capitalismo ${ }^{63}$, con la consiguiente intervención en el plano económico en un grado importante ${ }^{64}$. Más adelante nos detendremos en esta última cuestión.

Conviene además reseñar que en algunos ámbitos, al menos determinadas facciones del régimen estaban participando y disfrutando de la industria musical. Podemos, por ejemplo, referirnos a una gala organizada por el regimiento de infantería en Pontevedra, con ocasión de la festividad de la Inmaculada. El evento se celebró en diciembre de 1942, fue presidido por el General Jefe de la división 82 y contó con la asistencia de autoridades militares y civiles. En su programa encontramos numerosos temas calificados como fox-swing, además de la participación de Tejada y su Gran Orquesta ${ }^{65}$. No se trata de un caso aislado. Coetáneamente, Radio Salamanca emitiría una actuación de Los Magos del Jazz, una orquesta del Hogar del Soldado del regimiento de infantería número 28, cuyo Coronel había autorizado la intervención musical ${ }^{66}$. Todo ello induce a pensar que no parece que hubiera acuerdo con respecto a prohibiciones como la que consideramos; una circunstancia que no debió favorecer la

\footnotetext{
${ }^{61}$ En 1939 se denegó, aunque con carácter circunstancial, una ampliación de la fábrica de discos, según se informa en "Los comienzos de la industria discográfica en Euskal Herria", op. cit. Hemos localizado la fuente original que recoge la resolución en "[Denegación de autorización para la ampliación de la fábrica de Discos Columbia]", Boletín Oficial del Estado, 34, 3 de febrero de 1939, p. 668. A nuestro modo de ver, se trata de una manifestación de los intereses autárquicos del régimen. En la referencia citada puede leerse lo siguiente: "[...] constituyendo lo solicitado más bien ampliación de importación que ampliación de industria".

${ }^{62}$ La manifestación puede localizarse en la siguiente referencia, procedente de la Delegación Nacional de Propaganda y destinada a ser leída en las emisoras: Artículo No 79. Porque Combatimos la Musica Negra, 25 de junio de 1943. AGA (03)49.01 21/00701.

${ }^{63}$ DÍAZ, E.; op. cit., pp. 30, 33.

${ }^{64}$ KELSEN, H.; Teoría general del derecho y del Estado, García Máynez, E. (trad.), México, Universidad Nacional Autónoma de México, $3^{\text {a }}$ ed., 2008, p. 360.

65 “Actos con los que se festejará el día de la Purísima Concepción”, El pueblo gallego. Diario de Falange Española tradicionalista y de las JONS, 6 de diciembre de 1942, p. 6.

66 “«Los Magos del Jaz» en Radio Salamanca”, El Adelanto. Diario de Salamanca, 4 de diciembre de 1942, p. 3.
} 
proliferación de aquellas, ni su extensión a otros ámbitos, y que probablemente se reforzase con el devenir del conflicto bélico internacional.

En el contexto de la II Guerra Mundial habían tenido lugar una serie de acontecimientos que, sumados a las derrotas alemanas posteriores, llevarían al régimen a declararse neutral en octubre de $1943 \mathrm{y}$, con ello, a cierta relajación calculada, en lo que toca al tratamiento de la música estadounidense ${ }^{67}$. Quizá la ausencia de más prohibiciones sobre temas de swing, pudiera considerarse una manifestación temprana de aquello, determinada por los sucesos inmediatamente posteriores a la aparición de la Circular 98, que comenzarían a difuminar las expectativas sobre la victoria del Eje. Aproximadamente un mes y medio después de que fuera firmada la norma, las tropas Aliadas se disponían a abrir un nuevo frente desembarcando en el norte de África y, aunque en un clima de tensiones, ya entonces se manifestaría la neutralidad con respecto a los planes de aquellas ${ }^{68}$.

Además de lo anterior, en el análisis de las cuestiones que nos ocupan en este espacio deberían considerarse también los ingresos económicos que proporcionaba la industria musical ${ }^{69}$. El propio 78 rpm de Ébano swing y Cachita que hemos consultado recoge una prueba evidente de ello. En una de sus carátulas conserva el sello del impuesto que debía pagarse con el siguiente texto: "Columbia / San Sebastián / Imp. ${ }^{\circ}$ de lujo a meta- / lico-Permiso n. 856"70. En relación a esta cuestión, resulta representativo señalar que el consumo de lujo había supuesto en 1941 un ingreso de 426.617 pesetas, y que en el año siguiente ascendería a 502.435 pesetas. En ambos casos, se trata de las cifras más elevadas, en comparación con el resto de conceptos considerados en la relación que hemos consultado $^{71}$.

\footnotetext{
${ }^{67}$ Sobre ello IGLESIAS, I.; La modernidad elusiva ..., p. 130.

${ }^{68}$ MARQUINA, A.; “El Plan Backbone: España, bajo dos amenazas de invasión”, UNISCI. Discussion Papers, 36, 2014, p. 139, https://www.ucm.es/data/cont/media/www/pag-72480/UNISCIDP36-11MARQUINA.pdf.

${ }^{69}$ Cita esta circunstancia IGLESIAS, I.; La modernidad elusiva ..., p. 125.

${ }^{70}$ No hemos podido determinar con precisión la base jurídica de tal impuesto, pero consideramos que podría enmarcarse en la "Ley de 16 de diciembre de 1940 de reforma tributaria”, Boletín Oficial del Estado, 357, 22 de diciembre de 1940, pp. 8757, 8758. En estas páginas encontramos el inicio del capítulo dedicado a "Contribución sobre usos y consumos".
}

71 “Contribución de Usos y Consumos", Anuario Estadístico de España, sin número, 1951, p. 476, http://www.ine.es/inebaseweb/pdfDispacher.do;jsessionid=5FE8B4ACF95E4EC147F5A9B803C59BF2.inebaseweb02?td=166147. 
Los ingresos también procedían de las tarifas establecidas a mediados de 1942 (en la antesala de la prohibición que analizamos), en lo que respecta a temas coreados o con animación. A propósito de ello se señalaba lo siguiente ${ }^{72}$ :

"En los cabarets, dancings, salones de té, super-tangos, bares, etc., en los que actúe un «animador» o cuando actúen orquestas que puedan corear o coreen uno, varios o todos los números, se aplicará la tarifa de ejecución en vigor desde $1 .^{\circ}$ de julio último, aumentada en un 30 por 100 por el expresado concepto «Coreables», sea cualquiera la categoría del local y de la población".

En el mismo documento se define la palabra 'animador' del siguiente modo: "artista que, formando o sin formar parte integrante de orquesta, actúe dentro de la composición de la misma"73. Se da la circunstancia de que buen número de temas, incluidos los que pudieran enmarcarse en el swing, entraban dentro de las características citadas. A propósito de ello, resulta representativa la lista de vocalistas que ofrece Pujol Baulenas, en el marco de la primera mitad de 1942. En tal contexto, la misma fuente destaca la fama de Raúl Abril ${ }^{74}$. Se trata, precisamente, del intérprete de una de las versiones que hemos localizado de Ébano swing, en la que, por cierto, se incluye una letra que no aparece en el registro de Tejada y su Gran Orquesta. Es decir, nos encontramos con una versión a cargo de un animador y coreada, que probablemente contaría con una fama considerable, habida cuenta de lo señalado anteriormente sobre su intérprete; aunque como consecuencia de la prohibición, no generaría ingresos ni por su emisión, ni por su interpretación en lugares públicos. A propósito de esto último, debe señalarse que en la antesala de la prohibición, al menos alguna de las versiones emitidas del tema contó con animadora ${ }^{75}$.

Ciertamente, una prohibición como la que nos viene ocupando podría ser asumible, en términos de ausencia de ingresos por conceptos como los señalados. Sin embargo, la cuestión cambia si hubieran

\footnotetext{
72 “Tarifas. Coreables animadores y otras modalidades”, Boletín del Sindicato Nacional del Espectáculo, 3, 15 de junio de 1942 , p. 13.

${ }^{73}$ Ibídem.

74 PUJOL BAULENAS, J.; op. cit., pp. 116, 117.

${ }^{75}$ Así, en el caso de la emisión de Radio Madrid, por parte de una vocalista anunciada como 'Maricarmen'. [Cuaderno de emisiones de] Radio Madrid, op. cit.
} 
tenido lugar sucesivas prohibiciones de temas musicales, pues la cantidad no recaudada habría aumentado considerablemente.

Para concluir este apartado, quisiéramos referirnos también a otras razones que enlazan con alguno de los aspectos que consideraremos en el siguiente espacio. Sin duda, el hecho de ir prohibiendo tema por tema, en el caso de que la opción se hubiera contemplado, debió verse como tarea excesivamente tediosa e inasumible en términos humanos y materiales. Por otra parte, podría haberse considerado que con la entrada en vigor de la Circular 95, que prohibía el swing en general, no sería necesaria la labor anterior; un argumento que, no obstante, no puede plantearse sin, al mismo tiempo, cuestionar la aparición de la Circular 98, posterior a la 95. Las pretensiones totalitarias que consideramos anteriormente, de nuevo entrarían en tensión con la complejidad burocrática que comportaba la puesta en la práctica. Sin embargo, no parece que con ello se renunciase a las aspiraciones de control, sino más bien a desistir de la vía normativa para llevar a cabo tal cometido, en lo que respecta a temas concretos. A propósito de ello, resulta interesante constatar que en la nota en la que se informaba de la prohibición del tema Bésame mucho (datada en septiembre de 1943, la última de las que hemos considerado desde el punto de vista cronológico), podemos leer en su parte final lo siguiente ${ }^{76}$ :

"Lo que te traslado para tu conocimiento y cumplimiento, deseando que en lo sucesivo sea vuestra la iniciativa de suspender la radiación de discos y en general piezas musicales como cantables que por su chabacaneria están tan lejos del buen gusto.”

En todo caso, vemos, de nuevo, que el texto hace referencia al ámbito radiofónico, y que ordena censuras ad hoc; detalles detrás de los cuales, probablemente deban advertirse varios de los intereses considerados en este apartado.

${ }^{76}[$ Nota con la prohibición de Bésame mucho], op. cit. 


\section{Deficiencias normativas}

\section{1. La Circular 98}

En el espacio que ahora comenzamos, dedicado al análisis normativo, nos vamos a fijar en numerosos aspectos que acusan una técnica normativa deficiente ${ }^{77}$ (aun cuando, paradójicamente, algunas de las recomendaciones propias de este ámbito estuvieron presentes en el momento ${ }^{78}$ ); una circunstancia de la cual se derivan resultados contrarios al imperio de la ley ${ }^{79}$. Con ello aportamos argumentos que ofrecen muestra del carácter totalitario del régimen al que nos referimos anteriormente (teniendo en cuenta ahora su oposición al Estado de Derecho); tanto en lo que respecta a la Circular 98, que centrará la atención de este espacio, como en lo concerniente a las regulaciones relacionadas con aquella, también dedicadas a la censura musical, que consideraremos en el siguiente apartado.

Como sabemos, la Circular 98 se mandó a las Delegaciones Provinciales que, a su vez, la debían remitir a las emisoras. Sin embargo, conviene tener en cuenta que la norma iba a afectar a numerosos colectivos, además de aquel que tuviese encomendada la tarea de llevar a cabo la censura. A modo de ejemplo, podemos pensar en las orquestas que tuvieran en sus repertorios los temas prohibidos y que se dispusieran a interpretarlos en espectáculos radiados, quienes se encargasen de organizar dichos eventos, o bien quienes pretendieran interpretar música en los estudios de las emisoras. Sin embargo, ante esta circunstancia nos encontramos con que la Circular 98 se había distribuido en la forma recientemente apuntada, pero no se publicó. Cabe entender, por tanto, que varios colectivos afectados por aquella no tuvieron conocimiento de la misma.

Por otra parte, el texto de la propia norma da lugar a plantear las siguientes cuestiones. De un lado, la generalidad en el contenido queda considerablemente reducida. Es cierto que no se establece un acto individual, pero la restricción en el rasgo citado suscita problemas tales como desigualdades en el tratamiento (otros temas de swing quedaban fuera de prohibición, al menos en lo que respecta a esta norma), o la tremenda complejidad que supondría plantear una regulación musical secundando la

\footnotetext{
77 Sobre varias de las cuestiones que consideraremos desde dicha perspectiva, puede verse ZAPATERO, V.; El Arte de Legislar, Pamplona, Thomson-Aranzadi, 2009, pp. 256 y ss.

${ }^{78}$ Así, por ejemplo, en PÉREZ SERRANO, N.; “El nuevo Código Civil italiano”, Revista Crítica de Derecho Inmobiliario, 143, 1940, p. 165.

${ }^{79}$ Sobre ello LAPORTA, F., J.; El imperio de la ley. Una visión actual, Madrid, Trotta, 2007, p. 92.
} 
misma fórmula ${ }^{80}$. Como puede advertirse, tal circunstancia está en conexión con la última parte del desarrollo planteado en el apartado precedente, en el cual pretendíamos buscar posibles causas del escaso desarrollo de prohibiciones llevadas a cabo en la línea que presenta la que nos ocupa.

Además, el texto de la Circular 98 da lugar a plantear una reflexión sobre la claridad en el lenguaje, recomendación que también ha de preservarse si no se quiere afectar negativamente al imperio de la ley, en aspectos tales como la falta de seguridad jurídica en la aplicación de la norma ${ }^{81}$. Aunque, como sabemos, el contenido de aquella es breve, en él detectamos una imprecisión. Recordemos que la prohibición del segundo tema se presenta como sigue: “"Cachita» swing de R. Hernández”. Este texto da a entender que la persona citada había compuesto un swing, pero no fue así; estamos ante una interpretación swing de una rumba de R. Hernández ${ }^{82}$. Tal circunstancia invita a pensar que quien redactó el texto de la norma no interpretó correctamente el contenido de la carátula del $78 \mathrm{rpm}$. En ella leemos “Cachita / (R. Hernández) - «Swing»”; es decir, el título del tema, la persona que lo compuso y el estilo musical en el que se enmarca la versión de la grabación, no la original. Siguiendo la intención de la norma (recordemos lo dicho a propósito de su elaboración), debía haberse prohibido la versión swing del tema en cuestión, y no propiamente el tema en sí; que es la conclusión a la que induce el texto normativo, sumando a ello la idea errónea de que se trata de un tema swing en su origen. Como veremos más adelante, la circunstancia se dejaría notar en la puesta en práctica de la censura.

Además de los aspectos anteriores, conviene también que centremos la atención en el sistema sancionatorio para aquellos casos de incumplimiento de la norma. La Circular 98 no presenta contenido alguno en este sentido. En principio, podemos decir que nos encontramos ante lo que hoy conocemos como laguna normativa ${ }^{83}$, que hace referencia a la existencia de un supuesto de hecho para el que no se prevé consecuencia jurídica. No obstante, cabría considerar que, por vía interpretativa, podrían aplicarse las sanciones de la Circular 95, que había prohibido el swing en términos generales. Sin

\footnotetext{
${ }^{80}$ Sobre las cuestiones consideradas, en términos generales, LAPORTA, F. J.; op. cit., pp. 86, 87. Aunque, como señalamos, la norma no contempla un acto individual, la reducción de la generalidad suscita efectos negativos en los ámbitos que quedan afectados en aquel supuesto.

${ }^{81}$ ZAPATERO, V.; op. cit., pp. 257 y ss.; LAPORTA, F. J.; op. cit., p. 93.

${ }^{82}$ Puede ser interesante consultar la siguiente referencia, donde a continuación de Cachita figura "rumba R. Hernández": Xavier Cugat and his Waldorf-Astoria Orchestra, "Cachita/Duerme (Time was)", U.S.A., Columbia, 1941. 78 rpm. BNE/DS/14486/12.

${ }^{83}$ Sobre ello GUASTINI, R.; "Proyecto para la voz «ordenamiento jurídico» de un diccionario", Doxa, Cuadernos de Filosofía del Derecho, 27, 2004, pp. 276, 277.
} 
embargo, aun en el caso de que pudiera aceptarse tal planteamiento, con él debe constatarse que dicho sistema sancionatorio también suscita complicaciones, pues, por ejemplo, no contempla el órgano competente que debía establecer la sanción ${ }^{84}$. Nos encontramos, por tanto, ante importantes afectaciones al imperio de la ley, que solicita en la materia que nos ocupa, tanto precisión, como un control exigente ${ }^{85}$.

\section{2. El análisis con respecto a otras normas}

La línea de desarrollo que venimos planteando resulta aún más sugerente si se tiene en cuenta la norma que nos interesa, y otras relacionadas con ella en lo que respecta a la música que se estaba censurando. Desde esta perspectiva, en principio debe señalarse que la prohibición de la Circular 98 resulta sorprendente, por cuanto incide en un ámbito que ya se había regulado inmediatamente antes en la Circular 95. Como ya señalamos, en esta última se había prohibido el swing en la radio. La aparición de ambas normas debió generar confusión en lo que respecta a la forma en la que debía llevarse a cabo la censura. La Circular 98 pudo haber inducido a pensar que desde la Delegación Nacional de Propaganda se irían remitiendo sucesivas prohibiciones del mismo tipo y que, por tanto, a la hora de llevar a cabo la censura debía atenderse a las proscripciones concretas. No obstante, de ser así se estaría restando eficacia a la Circular 95.

Es cierto que la circunstancia anterior debió verse en un sentido diferente, al menos en determinados entornos como Radio Madrid, donde se recibió una copia de la Circular 95 con fecha de 23 de septiembre (se trata de una versión de la misma norma citada anteriormente, que incluye ligeras variaciones en aspectos tales como la enumeración de ítems ${ }^{86}$ ). Como sabemos, la Circular 98 tiene fecha de 22 de septiembre. En principio, cabría señalar que esta disposición no deja de inducir a confusión, pues la Circular 98, numéricamente posterior a la 95, está fechada un día antes que la última citada. En cualquier caso, ello podría haber dado lugar a pensar que debía tenerse en cuenta la prohibición general del swing, en vez de la concreta, fechada un día antes. A efectos prácticos, quizá

\footnotetext{
${ }^{84}$ En esta ocasión nos encontramos con lo que hoy conocemos como laguna técnica, que tiene lugar cuando falta una norma que resulta necesaria para la eficacia de otra norma. Sobre ello GUASTINI, R.; op. cit, p. 277.

${ }^{85}$ LAPORTA, F. J.; op. cit., p. 94.

86 Circular 95. Normas sobre Censura Radiofonica, 23 de septiembre de 1942. AGA (03)49.01 21/00806.
} 
podría haber sido esta última la interpretación adoptada, si se tiene en cuenta que la Circular 95 entraría en vigor el 1 de octubre ${ }^{87}$.

Además de todo lo anterior, cabría añadir que las prohibiciones contra el swing no se elaboraron exclusivamente por la Delegación Nacional de Propaganda. Las Delegaciones Provinciales también establecieron sus propias normas. De entre las que hemos tenido oportunidad de consultar, nos ha parecido especialmente interesante para este trabajo la Circular 54 de la Delegación Provincial de Tarragona. En ella encontramos la siguiente lista de temas prohibidos ${ }^{88}$ : “Arroz con Leche -Rancherita. / Ebano Swing - Fox Trot. / Rancherita - Swing. / Coplas del Espartero / Sevillanas del Espatero.”

En base a la relación transcrita, puede decirse que lo que se pretendió con la Circular 54 fue incluir todas las referencias que la Delegación Nacional de Propaganda había ido prohibiendo, valiéndose de circulares centradas en temas concretos. No obstante, debe hacerse notar que la técnica utilizada no está exenta de incorrecciones. El tema Rancherita que, como hemos visto, se califica musicalmente en la relación anterior como swing, no había sido censurado por la Delegación Nacional de Propaganda. De hecho, no tenemos noticia de su grabación. ¿Cómo podría explicarse su presencia en la lista? Pensamos que fue el resultado de un error, consistente en escribir Rancherita, en vez de Cachita, que es el tema prohibido por la Circular 98. No es gratuito el detalle de que en la lista anterior, aquel título aparezca a continuación de Ébano swing (como sabemos, este último y Cachita fueron los registros que había prohibido la norma citada). Cabría pensar además que la calificación musical de Arroz con Leche como 'Rancherita', podría haber contribuido a la disposición que encontramos.

De la circunstancia expuesta resulta una inconsistencia normativa entre la Circular 98 y la Circular 54 de la Delegación Provincial de Tarragona, y lo mismo cabría decir a propósito de las normas procedentes de otras Delegaciones Provinciales. En el caso de que en estas últimas se hubieran reproducido los temas prohibidos, o bien se remitieran a los mismos, también podría observarse inconsistencia (suponiendo la corrección en la transcripción, en el caso de que la misma hubiera tenido lugar); pues Cachita habría aparecido como uno de los temas prohibidos que, como sabemos, no había sido contemplado por la Delegación Provincial de Tarragona a consecuencia de la circunstancia

\footnotetext{
${ }^{87}$ Este dato se comparte en las dos versiones consultadas.

${ }^{88}$ Circular 54. [Prohibiciones musicales de la Delegación Provincial de Tarragona], 7 de noviembre de 1942. AGA (03)49.01 21/01533.
} 
expuesta. Así, por ejemplo, habría acontecido con las normas de la Delegación Provincial de Huesca, donde se hace referencia a los temas prohibidos por la Delegación Nacional de Propaganda ${ }^{89}$.

Por otra parte, conviene que detengamos también la atención en el siguiente extracto de la Circular 5490:“Los Delegados Locales de Propaganda deberán velar por el cumplimiento de lo ordenado, dando traslado de la presente circular a cuantas asociaciones culturales o filarmónicas, Orquestinas, Cines, etc. existan en la localidad". Como puede observarse, este texto amplía la ocasión de la norma ${ }^{91}$, concretamente en lo que respecta a la coordenada espacial ${ }^{92}$, alcanzando a contextos que no contempla la Circular 98. Recordemos que esta última se refiere al ámbito radiofónico. Tal circunstancia invita a pensar que las aspiraciones totalitarias tuvieron también proyección en entornos provinciales como el considerado. Por otra parte, desde la perspectiva formal debe señalarse que en este punto la redacción de la Circular 54 es imprecisa, a consecuencia del uso de la abreviatura 'etc.' En base a la misma, debe entenderse que la relación de espacios que presenta no es numerus clausus, y que tal disposición podría suscitar dudas como, por ejemplo, si en una verbena un trío musical pudiera interpretar los temas prohibidos.

Por lo demás, cabría añadir que la consideración planteada anteriormente en lo que respecta al sistema sancionatorio, podría ser también extrapolable a la Circular 54. Es cierto que en esta última se hace referencia a las sanciones, pero con una fórmula nada proclive a favorecer la seguridad jurídica. El texto en esta ocasión informa de que la transgresión de la norma "será severamente sancionada" 93 . Quedaba, por tanto, claro que el incumplimiento conllevaría sanción, pero no se especifica nada sobre el órgano que la impondría o el quántum de aquella. Es cierto que posteriormente, desde una perspectiva general, se trató de concretar la primera cuestión, pero curiosamente se estableció el cargo que debía imponer la sanción (que tampoco se cuantifica en esta ocasión), en función de la menor o mayor gravedad de la infracción. En cualquier caso, conviene constatar que desde que aparecieron las

\footnotetext{
89 "Normas Generales Confeccionadas por la Delegación Provincial de Huesca para las Delegaciones Comarcales Dependientes de la Misma Regulando sus Actividades de Propaganda", en ABELLÁN, M. L.; Censura y creación literaria en España (1939-1976), Badalona, Ediciones Península, 1980, p. 274.

${ }^{90}$ Circular 54, op. cit.

${ }^{91}$ La circunstancia también se aprecia, aunque con un formato más general, en "Normas Generales Confeccionadas por la Delegación Provincial de Huesca..." op. cit., p. 244.

92 Sobre la cuestión LAPORTA, F. J.; op. cit., p. 90.

${ }^{93}$ Circular 54, op. cit.
} 
circulares que nos interesan, hasta la llegada de la Circular 14294, que recoge los contenidos recientemente expuestos, quienes ejercieron la censura no contaron con criterios para llevar a cabo aquella en materia sancionatoria.

\section{La eficacia de la censura}

Como sabemos, la Circular 98 está fechada el 22 de septiembre de 1942. Cabría entender que comenzaría a aplicarse días después, una vez recibida en las Delegaciones Provinciales y trasladada desde estas últimas a las emisoras. Sin embargo, no parece que en todo caso fuera así. Encontramos prueba de ello en la Emisora local de Madrid, que debió implementar la norma a partir del 22 de enero de 1943, es decir, cuatro meses después de que hubiera sido firmada. Así hemos de entenderlo, si tenemos en cuenta una nota de servicio interior en la que el Director de la emisora informaba al Jefe de programación musical de la prohibición en cuestión, junto con el resto de las que habían recaído sobre otros temas concretos ${ }^{95}$. Desconocemos las causas del retraso, pero no puede atribuirse a los métodos de envío de la época (en otros casos no se aprecia una demora tan dilatada).

El documento recientemente citado ofrece también prueba de alguna incorrección en el desarrollo de la censura. Curiosamente, en respuesta a la orden recogida en la nota de servicio interior recientemente citada, el Jefe de programación musical informaba de que daría de baja de la programación el disco Cachita, pues "l ba Swing [sic.] ${ }^{96}$, y Arroz con leche" no estaban en la discoteca97. Con ello, muy probablemente se estaba informando de la retirada de un disco que no había sido censurado; una consecuencia que, según pensamos, trae causa de la incorrección que hicimos constar anteriormente, en lo que respecta a la redacción de la prohibición del tema Cachita.

Como ya señalamos, la Circular 98 da a entender que se estaba prohibiendo el tema Cachita, cuando lo que se pretendía era prohibir la interpretación swing de aquel. Al menos hasta donde llegamos a conocer, únicamente se editó una versión del tema con dicha característica, que es la que aparece en el

\footnotetext{
94 Circular 142. Normas a las Delegaciones Provinciales de Educación Popular sobre Circulares dirigidas a las localidades de su jurisdicción y sobre la forma de verificar los expedientes de Inspección para sancionar lasinfracciones [sic.], 25 de junio de 1943. AGA (03)49.01 21/00807.

${ }^{95}$ Nota de servicio interior. De Director de la emisora a Jefe de programación musical, 22 de enero de 1943. AGA (03)49.01 21/01836.

${ }^{96}$ Pensamos, sin duda, que ha de entenderse Ébano swing.

${ }^{97}$ Nota de servicio interior, op. cit.
} 
78 rpm que incluía en la otra cara el tema Ébano swing. De este modo, si el Jefe de programación musical confirmó que este último no se encontraba en la discografía de la emisora, debe pensarse entonces que estaba retirando un disco distinto; es decir, la grabación del tema Cachita en un registro musical que no se enmarcaba en el swing. Podrían considerarse varias opciones en este sentido: es posible que estemos ante una versión en clave de rumba del tema en cuestión, también a cargo de Tejada y su gran Orquesta ${ }^{98}$; o quizá con la interpretación de Xavier Cugat and his Waldorf-Astoria Orchestra $^{99}$. En ambos supuestos estamos ante versiones no prohibidas, pues no se trata de música swing.

En todo caso, y aun a pesar de circunstancias como las anteriores, consideramos que el hecho de que aparecieran prohibiciones de temas concretos como la que nos ocupa, redundó en una censura más eficaz que aquella que puede percibirse a propósito de las prohibiciones de la música negra y del swing en términos generales. Como sabemos, estas últimas se habían establecido en la Circular 95. Hemos tenido oportunidad de revisar numerosos cuadernos de emisiones de diferentes emisoras, y el resultado de este trabajo demuestra que en ellos hay temas que pueden enmarcarse en el jazz ${ }^{100}$, que, al menos en principio, debería considerarse proscrito, por cuanto se trata del primer tipo de música prohibido. Del mismo modo, hemos localizado temas que podrían enmarcarse en el swing, y que incluso en algunas ocasiones reflejan en su título dicho tipo de música. Así acontece en un programa de baile de Radio Madrid, donde aparece Harlem swing interpretado por la Orquesta Andrés Moltó ${ }^{101}$. En otras ocasiones, la referencia se encuentra en la tipología musical, como, por ejemplo, en la cita del tema $E l$ Cuarto azul, que hemos localizado con la categoría de fox-swing en un programa de las Emisoras Regional de Onda Corta y Local de Onda Media de Málaga ${ }^{102}$. Conviene, no obstante, reseñar que estos casos son mucho menos frecuentes que los referidos en primer lugar.

Por otra parte, como adelantábamos, la censura del tema Ébano swing parece que fue más eficaz en términos generales. Únicamente lo hemos localizado, sin tacha alguna de censura, en un programa de

\footnotetext{
${ }^{98}$ Puede localizarse en Catálogo general de discos Columbia publicados hasta mayo de 1942, op. cit., p. 88.

${ }^{99}$ Xavier Cugat and his Waldorf-Astoria Orchestra, op. cit.

${ }^{100}$ La cuestión se considera en IGLESIAS, I.; La modernidad elusiva ..., p. 129; si bien, teniendo en cuenta el trabajo que presentamos, entendemos que cabría reconsiderar la afirmación de que la prohibición del swing no se aplicaba a la música instrumental.

101 [Cuaderno de emisiones de] Radio Madrid, 4 de octubre de 1943. AGA (03)48 21/00227.

102 [Cuaderno de emisiones de] Emisoras Regional de Onda Corta y Local de Onda Media de Malaga, 18 de octubre de 1943. AGA (03)48 21/00252.
} 
las Emisoras Regional de Onda Corta y Local de Onda Media de Málaga; concretamente, en una entrada con el siguiente texto, que sin duda hace referencia al $78 \mathrm{rpm}$ de la agrupación que en el mismo se menciona: “«Ebano Swing» Fox trot y «Madrugada» Fox lento por Raul Abril con la Orquesta Martín de la Rosa"103.

Estos resultados dan razones para pensar que, probablemente, a la hora de llevar a cabo la censura musical, la aparición de la palabra 'swing' en los cuadernos de emisiones debió resultar especialmente sospechosa, por cuanto manifestaba claramente la presencia de música prohibida. Cabe suponer que la misma circunstancia, incluso con más fuerza, habida cuenta de la concreción de la prohibición, se habría tenido en cuenta en el caso de que apareciera en los programas el título Ébano swing.

Lo anterior no quiere decir que no se emitieran temas de swing, que quizá podrían pasar desapercibidos si su título no diera cuenta explícita de aquella música, o bien a consecuencia de ingeniosos intentos para sortear la censura. Resulta muy interesante constatar que, por ejemplo, en un programa de Radio Barcelona aparece censurada la siguiente entrada: "«Siguiendo el ritmo» Fox swing, de Crespo (de Tejada y su Gran Orq.)". A partir del tachado que se hace del texto surge una flecha hacia el pie de página, donde puede leerse con letras manuscritas y grandes esta advertencia: “swing, no puede radiarse!""104. Consideramos que muy probablemente, en este caso la censura se debió a la calificación musical del tema ("Fox swing"), que marca como estilo de música el swing. Prueba de ello es que en un programa posterior de la misma emisora, radiado dos meses y medio después, encontramos la siguiente entrada sin signo alguno de censura: "Siguiendo el Ritmo, Fox de Crespo"105. Como puede verse, en esta ocasión se suprimió la palabra 'swing' que sí figuraba en la calificación musical de la entrada citada en primer lugar. La 'táctica', por lo demás, no era nueva. Como vimos, incluso antes de que aparecieran las prohibiciones contra el swing, algunas emisoras estaban procediendo de forma parecida a la hora de anunciar el tema Ébano swing. La razón de que no encontremos tal circunstancia en los meses siguientes se debe, entendemos que sin duda, a la prohibición concreta de aquel que recogió la Circular 98.

103 [Cuaderno de emisiones de] Emisoras Regional de Onda Corta y Local de Onda Media de Malaga, 14 de octubre de 1943 . AGA (03)48 21/00252.

104 [Cuaderno de emisiones de] Radio Barcelona, 28 de junio de 1943, http://ddd.uab.cat/pub/guiradben/1943/guiradben_a1943m6d28.pdf.

105 [Cuaderno de emisiones de] Radio Barcelona, 13 de septiembre de 1943, https://ddd.uab.cat/pub/guiradben/1943/guiradben_a1943m9d13.pdf. 
Para concluir este espacio quisiéramos dejar constancia de un detalle que puede extraerse del desarrollo anterior. Como hemos visto, la censura parece que centró la atención, aunque con diferentes procedimientos, en los temas Ébano swing y Siguiendo el ritmo. Curiosamente, ambos fueron compuestos por Santiago Crespo y se interpretaron por Tejada y su Gran Orquesta. Esta coincidencia no da razones suficientes para concluir que compositor y orquesta hubieran sido proscritos, algo de lo cual no tenemos conocimiento, y que se desmiente si, por ejemplo, comprobamos que en los cuadernos de emisiones aparece la orquesta citada. Sin embargo, la circunstancia invita a pensar que, probablemente, al menos en algunos casos, a la hora de llevar a cabo la censura se podrían haber considerado con especial detenimiento determinadas agrupaciones musicales o personas que hubieran compuesto temas.

\section{Conclusiones}

La Circular 98, que prohibió los temas Ébano swing y Cachita durante el primer franquismo, puede considerarse una manifestación del totalitarismo del régimen, o bien de sus intenciones en este sentido. Estamos ante una medida más, desarrollada en el marco de los objetivos de aquel, para preservar la unidad de la patria y la lucha contra el enemigo. Además, supuso un enfrentamiento al Estado de Derecho en diferentes sentidos (afectación de derechos y del imperio de la ley, como así se confirma con un análisis normativo); y una prueba de las aspiraciones de control de un régimen que, además, se caracterizaba por tener un partido único con una ideología difundida con fuerza y persuasión en los medios.

Cabría añadir que el hecho de centrar la atención en las composiciones citadas fue totalmente arbitrario. Muy probablemente, el tema Ébano swing se prohibió porque había cobrado cierta fama y aparecía frecuentemente en los programas de radio; y el tema Cachita, simplemente, porque se recogía en versión swing en el 78 rpm que incluía el tema citado en primer lugar.

No obstante, conviene precisar que las aspiraciones totalitarias del régimen, relativas al tema del control, entran en tensión con circunstancias tales como que la prohibición se planteara en el ámbito radiofónico, o que no proliferaran proscripciones en la misma línea. En el análisis de las posibles causas de todo aquello encontramos la preservación de los intereses del régimen, posibles desacuerdos sobre las medidas musicales, circunstancias de la II Guerra Mundial que comenzaban a cuestionar la 
victoria del Eje (algo que presentaría la ausencia de prohibiciones futuras como un antecedente de aquella permisividad interesada que se apreciaría posteriormente), pretensiones recaudatorias o complejidades burocráticas.

La afectación al Estado de Derecho constatada anteriormente, y concretada en el imperio de la ley, se demuestra a partir del análisis de la Circular 98; una norma que no se publicó, aun cuando afectaría a varios colectivos, con una considerable reducción en la generalidad de su contenido, carente de una respuesta sancionatoria y con una técnica lingüística deficiente que, al menos parcialmente, proporcionaría una implementación errónea de la censura en lo que respecta al tema Cachita.

La misma conclusión cabría extraer de un análisis ampliado a otras normas coetáneas relacionadas con la anterior, y también dedicadas a la censura musical. En principio, desconcierta la aparición de una prohibición concreta de dos temas de swing, justo después de que se hubiera firmado la Circular 95, que prohibía aquella música en términos generales. Además, en este último caso se distribuyó una versión diferente de la norma, con fecha posterior a aquella que apareció en la Circular 98. Tal circunstancia podría haber suscitado confusión.

Por otra parte, si ampliamos el análisis al ámbito provincial resulta especialmente interesante la Circular 54 de la Delegación Provincial de Tarragona. Su texto transcribe los temas prohibidos por la Delegación Nacional de Propaganda, aunque incurriendo en un error en lo que respecta al tema Cachita. Ello suscita inconsistencias con la Circular 98 y con las normas procedentes de otras Delegaciones Provinciales. Además, la Circular 54 amplía la prohibición a otros ámbitos, más allá del radiofónico, dando muestra con ello del calado de las aspiraciones totalitarias en el plano provincial. Por lo demás, cabría añadir otras afectaciones al imperio de la ley, especificadas en imprecisiones que afectan tanto a la determinación del espacio de aplicación, como al sistema sancionatorio.

Finalmente, en lo que respecta a la eficacia de la prohibición debe decirse que su aplicación no fue inmediata en todo caso. No obstante, resulta interesante constatar que la Circular 98 debió ser más eficaz que la 95, al menos en lo que concierne a la prohibición de la música negra recogida en la última. Tal circunstancia invita a plantear un análisis con carácter prospectivo, tendente a detallar las posibles razones (probablemente de diferente tipo, pero entre ellas, ineludiblemente las normativas) que pudieran explicar tal circunstancia. 


\section{1. Bibliografía}

ARENDT, H.; Los orígenes del totalitarismo, Solana, G. (trad.), Madrid, Taurus Ediciones, 1974.

ARON, R.; Democracia y totalitarismo, González Castro, L. (trad.), Barcelona, Página Indómita, 2017.

BERMEJO SÁNCHEZ, B.; “La Vicesecretaría de Educación Popular (1941-1945): un «ministerio» de la propaganda en manos de Falange", Espacio, Tiempo y Forma, Serie V Historia Contemporánea, IV, 1991, http://espacio.uned.es/fez/eserv.php?pid=bibliuned:ETFSerie5-16946BB6-A601-59A9-CD02-

AB4BD2DA2738\&dsID=Documento.pdf.

BUNN, M.; "Reimagining Repression: New Censorship Theory and After”, History and Theory, 54, 2015.

CENTENERA SÁNCHEZ-SECO, F.; "El jazz en el III Reich: un análisis sobre los fracasos en la legalidad y la justicia”, Derechos y Libertades, 36, 2017, https:/e-archivo.uc3m.es/bitstream/handle/10016/26252/DyL-2017-36centenera.pdf? sequence $=1$.

CENTENERA SÁNCHEZ-SECO, F.; "The Frankfurt Hot Club jazz band under the Nazis: much more than music", Law and Humanities, 12/2, 2018, https://www.tandfonline.com/doi/abs/10.1080/17521483.2018.1514948.

"Contribución de Usos y Consumos", Anuario Estadístico de España, sin número, 1951, http://www.ine.es/inebaseweb/pdfDispacher.do;jsessionid=5FE8B4ACF95E4EC147F5A9B803C59BF2.inebaseweb02?td= $\underline{166147 .}$.

CLAVERO, B.; "Derecho bajo asedio, 1936-1939: República Española y Sociedad de Naciones en el escenario europeo entre constitucionalismo y dictadura", Quaderni Fiorentini per la storia del pensiero giuridico moderno, 47, 2018, http://www.centropgm.unifi.it/cache/quaderni/47/0263.pdf.

CLAVERO, B.; Evolución histórica del constitucionalismo español, Madrid, Tecnos, 1985.

CLAVERO, B.; Manual de historia constitucional de España, Madrid, Alianza Universidad Textos, 1989.

DÍAZ, E.; Estado de derecho y sociedad democrática, Madrid, Cuadernos para el Diálogo, 1966.

GARCÍA MARTÍNEZ, J. M.; Del fox-trot al jazz flamenco. El jazz en España: 1919-1996, Madrid, Alianza Editorial, 1996. GUASTINI, R.; "Proyecto para la voz «ordenamiento jurídico» de un diccionario", Doxa, Cuadernos de Filosofía del Derecho, 27, 2004.

HADAMOVSKY, E.; “Die Rede auf der Intendantentagung”, https://grammophon-platten.de/page.php?281.1.

IGLESIAS, I.; La modernidad elusiva. Jazz, baile y política en la Guerra Civil Española y el Franquismo (1936-1968), Madrid, Consejo Superior de Investigaciones Científicas, 2017.

IGLESIAS, I.; "Performing the 'anti-spanish' body", en Johnson, B. (ed.), Jazz and Totalitarianism, New York and London, Routledge, 2017.

JOHNSON, B.; “Introduction”, en Johnson, B. (ed.), Jazz and Totalitarianism, New York and London, Routledge, 2017.

KELSEN, H.; Teoría general del derecho y del Estado, García Máynez, E. (trad.), México, Universidad Nacional Autónoma de México, $3^{\text {a }}$ ed., 2008, p. 360.

KERSHAW, I.; Decisiones trascendentales. De Dunquerque a Pearl Harbour (1940-1941). El año que cambió la historia, Escartín, A. (trad.), Barcelona, Ediciones Península, 2008.

LAPORTA, F., J.; El imperio de la ley. Una visión actual, Madrid, Trotta, 2007. 
MARQUINA, A.; "El Plan Backbone: España, bajo dos amenazas de invasión”, UNISCI. Discussion Papers, 36, 2014, https://www.ucm.es/data/cont/media/www/pag-72480/UNISCIDP36-11MARQUINA.pdf.

MONTORO FRAGUAS, A.; "La Circular 95/42. Un documento singular en la censura de la radio española", Revista General de Información y Documentación, 6/1, 1996.

"Normas Generales Confeccionadas por la Delegación Provincial de Huesca para las Delegaciones Comarcales Dependientes de la Misma Regulando sus Actividades de Propaganda”, en ABELLÁN, M. L.; Censura y creación literaria en España (1939-1976), Badalona, Ediciones Península, 1980.

NÚÑEZ DÍAZ-BALART, M.; "Las palabras como armas: la propaganda en la Guerra Civil”, en Timoteo Álvarez, J. (ed.), Historia de los medios de comunicación en España. Periodismo, imagen y publicidad (1900-1990), Barcelona, Editorial Ariel, 1989.

PEDRO, J.; “'The purest essence of jazz' The Appropiation of Blues in Spain during Franco's Dictatorship”, en Johnson, B. (ed.), Jazz and Totalitarianism, New York and London, Routledge, 2017.

PÉREZ SERRANO, N.; “El nuevo Código Civil italiano”, Revista Crítica de Derecho Inmobiliario, 143, 1940.

PÉREZ ZALDUONDO, G.; La música en España durante el franquismo a través de la legislación (1936-1951), [Tesis Doctoral], [Granada], Universidad de Granada, 2002 (CD).

PIZARROSO QUINTERO, A.; "Política informativa: información y propaganda (1939-1966)", en Timoteo Álvarez, J. (ed.), Historia de los medios de comunicación en España. Periodismo, imagen y publicidad (1900-1990), Barcelona, Editorial Ariel, 1989.

PUJOL BAULENAS, J.; Jazz en Barcelona. 1920-1965, Barcelona, Almendra Music, 2005.

STOLLEIS, M.; El ojo de la ley. Historia de una metáfora, Fernández-Crehuet, F. (trad.), Madrid, Marcial Pons, 2010.

STOLLEIS, M.; "La idea de Estado de Derecho", en Presno Linera, M. Á. (coord.), La metamorfosis del Estado y del Derecho, Oviedo, Junta General del Principado de Asturias, 2014, https://www.unioviedo.es/constitucional/fundamentos/octavo/pdfs/Stolleis-EstadodeDerecho.pdf.

STOLLEIS, M.; La textura histórica de las formas politicas, Gutiérrez Gutiérrez, I. (trad.), Madrid, Marcial Pons, 2011.

ZAPATERO, V.; El Arte de Legislar, Pamplona, Thomson-Aranzadi, 2009.

\section{2. Catálogos}

Catálogo general de discos Columbia publicados hasta mayo de 1942, San Sebastián, Fábrica de Discos Columbia, [1942], http://www.eresbil.com/web/uploads/archivosGeneradorWeb/Catalogos/erelib NL0214COL 01 v.pdf.

Recopilación de los discos "Columbia” publicados desde $1^{\circ}$ de junio de 1942 hasta 30 de abril de 1944, San Sebastián, Fábrica de Discos Columbia, [1944], http://www.eresbil.com/web/uploads/archivosGeneradorWeb/Catalogos/erelib NL0214COL 02 v.pdf.

\section{3. Documentos de archivos}

Artículo No 79. Porque Combatimos la Musica Negra, 25 de junio de 1943. AGA (03)49.01 21/00701.

Circular 54. [Prohibiciones musicales de la Delegación Provincial de Tarragona], 7 de noviembre de 1942. AGA (03)49.01 21/01533.

Circular 94. [Prohibición de Arroz con leche del Trío argentino Irustare], 16 de septiembre de 1942. AGA (03)49.01 21/00806.

Circular 95. Normas sobre Censura Radiofonica, 17 de septiembre de 1942. AGA (03)49.01 21/00701. 
Circular 95. Normas sobre Censura Radiofonica, 23 de septiembre de 1942. AGA (03)49.01 21/00806.

Circular 98. [Prohibición de Ébano swing y Cachita], 22 de septiembre de 1942. AGA (3)49.01 21/00806.

Circular 106. [Prohibición de las Coplas del Espartero y Sevillanas del Espartero], 21 de octubre de 1942. AGA (03)49.01 21/00806.

Circular 142. Normas a las Delegaciones Provinciales de Educación Popular sobre Circulares dirigidas a las localidades de su jurisdicción y sobre la forma de verificar los expedientes de Inspección para sancionar lasinfracciones [sic.], 25 de junio de 1943. AGA (03)49.01 21/00807.

Circular 156. [Prohibición de toda nominación a Los Bocheros], 5 de noviembre de 1943. AGA (03)49.01 21/00807.

[Cuaderno de emisiones de] Emisoras Regional de Onda Corta y Local de Onda Media de Malaga, 14 de octubre de 1943. AGA (03)48 21/00252.

[Cuaderno de emisiones de] Emisoras Regional de Onda Corta y Local de Onda Media de Malaga, 18 de octubre de 1943. AGA (03)48 21/00252.

[Cuaderno de emisiones de] Radio Barcelona, 13 de septiembre de 1943, https://ddd.uab.cat/pub/guiradbcn/1943/guiradben_a1943m9d13.pdf.

[Cuaderno de emisiones de] Radio Barcelona, 28 de junio de 1943, http://ddd.uab.cat/pub/guiradbcn/1943/guiradbcn_a1943m6d28.pdf.

[Cuaderno de emisiones de] Radio España, 12 de septiembre de 1942. AGA (03)48 21/00007.

[Cuaderno de emisiones de] Radio Madrid, 4 de octubre de 1943. AGA (03)48 21/00227.

[Cuaderno de emisiones de] Radio Madrid, 5 de septiembre de 1942. AGA (03)48 21/00012.

[Cuaderno de emisiones de] Radio Madrid, 10 de septiembre de 1942. AGA (03)48 21/00012.

DE URRUTIA, F.; Proyecto de Reorganización del Servicio de Propaganda de F.E.T. y de las J.O.N.S., sin fecha [probablemente de octubre de 1941, teniendo en cuenta la documentación adjunta]. AGA (03)48 21/00127.

"Erste Liste unerwünschter musikalischer Werke", German Propaganda Archive, https://research.calvin.edu/germanpropaganda-archive/banned.htm.

Informe del Cursillo para Capacitacion de Propagandistas Organizado por esta Delegacion Provincial [de Albacete] y Celebrado en los Dias 9 al 15 de Noviembre de 1942. Día 11 (3 $3^{\mathrm{a}}$ sesión de trabajo). AGA (03)49.01 21/01531.

Nota de servicio interior. De Director de la emisora a Jefe de programación musical, 22 de enero de 1943. AGA (03)49.01 21/01836.

[Nota con la prohibición de Bésame mucho], 21 de septiembre de 1943. AGA (3)60 21/00805.

Oficio de la Delegación Nacional de Propaganda. P. Oral E. Musical, 22 de mayo de 1942. AGA (03)49.01 21/00102.

[Solicitud de envío urgente de discos a la Fábrica de Discos Columbia], 28 de abril de 1943. AGA (03)49.01 21/01836.

[Solicitud de envío urgente de discos a la Fábrica de Discos Columbia], 28 de julio de 1943. AGA (03)49.01 21/01836.

\section{4. Hemeroteca}

“Actos con los que se festejará el día de la Purísima Concepción”, El pueblo gallego. Diario de Falange Española tradicionalista y de las JONS, 6 de diciembre de 1942.

EFE; “En el Japón se prohibe la música anglosajona, especialmente de «jazz»”, La Nueva España, 15 de enero de 1943. 
“«Los Magos del Jaz» en Radio Salamanca”, El Adelanto. Diario de Salamanca, 4 de diciembre de 1942.

"Notas. Declaración de Guerra". Falange, 8 de agosto de 1940.

\section{5. Normas y otras disposiciones publicadas}

“Decreto número 180", Boletín Oficial del Estado, 89, 17 de enero de 1937.

“[Denegación de autorización para la ampliación de la fábrica de Discos Columbia]”, Boletín Oficial del Estado, 34, 3 de febrero de 1939.

“Grupo de Música. Orden”, Boletín del Sindicato Nacional del Espectáculo, 5, agosto de 1942.

"Ley de 16 de diciembre de 1940 de reforma tributaria", Boletín Oficial del Estado, 357, 22 de diciembre de 1940.

"Ley de 20 de mayo de 1941 por la que se transfieren los Servicios de Prensa y Propaganda a la Vicesecretaría de Educación de F.E.T. y de las J.O.N.S., que se crea por la presente ley", Boletín Oficial del Estado, 142, 22 de mayo de 1941.

“Ley de 29 de diciembre de 1938”, Boletín Oficial del Estado, 183, 31 de diciembre de 1938.

"Orden de 15 de julio de 1939 creando una Sección de Censura dependiente de la Jefatura del Servicio Nacional de Propaganda y afecta a la Secretaría General”, Boletín Oficial del Estado, 211, 30 de julio de 1939.

“Tarifas. Coreables animadores y otras modalidades", Boletín del Sindicato Nacional del Espectáculo, 3, 15 de junio de 1942.

\section{6. Recursos sonoros}

Luis Rovira y su Orquesta, Emil, vocalista, "Yodel en swing/Bailando en la azucarera (Swingin' at the sugar bowl)", Barcelona, Compañía del Gramófono Odeón, 1942.78 rpm. BNE/ Ds/56/8.

Orquesta Andrés Moltó, "Harlem swing/Engaños", Barcelona, Compañía del Gramófono Odeón, 1942. 78 rpm. BNE/Ds/56/14.

Orquesta Lionel Hampton, "My muchachito (my buddy)/Tiempo y swing”, Barcelona, Compañía del Gramófono Odeón, 1941. $78 \mathrm{rpm}$. BNE/Ds/73/11.

Quinteto del Hot Club de Francia, “Jeepers creepers/Swing 39”, San Sebastián, Fábrica de Discos Columbia, 1943. 78 rpm. $\mathrm{BNE} / \mathrm{Ds} / 131 / 15$.

Raúl Abril, con la Orquesta Martín de la Rosa, "Madrugada: fox lento de la película, Ritmo en las ondas/Ébano swing", Barcelona, Compañía del Gramófono Odeón, 1942.78 rpm. BNE/Ds/80/8.

Tejada y su Gran Orquesta del Pasapoga de Madrid, "Ebano Swing/Cachita", San Sebastián, Columbia, sin fecha. 78 rpm. Colección privada.

Xavier Cugat and his Waldorf-Astoria Orchestra, "Cachita/Duerme (Time was)", U.S.A., Columbia, 1941. 78 rpm. BNE/DS/14486/12.

\section{7. Recursos web no recogidos en las relaciones anteriores}

"Los comienzos de la industria discográfica en Euskal Herria", ERESBIL. Archivo vasco de la música, http://www.eresbil.com/web/tema-inddiseh/Pagina.aspx?moduleID=2419\&lang=es. 